\title{
Doctor of Radiography Curriculum: Comparison of the Perception of Radiography Lecturers and Radiography Students towards the Proposed Curriculum
}

\author{
Beatrice Ukamaka Maduka ${ }^{1}$, Anthony Chukwuka Ugwu², Bakky Ngozi Adirika ${ }^{3}$, Michael \\ Promise Ogolodom², Chinedu Anyanwu ${ }^{2}$ and Ebube Mmeli Onwughalu ${ }^{2}$ \\ ${ }^{1}$ Department of Medical Radiography and Radiological Sciences, Faculty of Health Sciences and Technology, College of Medicine, \\ University of Nigeria Enugu Campus, Nigeria
}

${ }^{2}$ Department of Radiography and Radiological Sciences, Faculty of Health Sciences and Technology, College of Health Sciences, Nnamdi Azikiwe University, Nigeria

${ }^{3}$ Department of Educational Foundations, Faculty of Education, Nnamdi Azikiwe University, Nigeria

*Corresponding author: Beatrice Ukamaka Maduka, Department of Medical Radiography and Radiological Sciences, Faculty of Health Sciences and Technology, College of Medicine, University of Nigeria Enugu Campus, Enugu State, Nigeria

\section{ARTICLE INFO}

Received: 彗 July 27, 2021

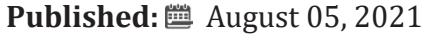

Citation: Beatrice Ukamaka Maduka, Anthony Chukwuka Ugwu, Bakky Ngozi Adirika, Michael Promise Ogolodom, Chinedu Anyanwu, Ebube Mmeli Onwughalu. Doctor of Radiography Curriculum: Comparison of the Perception of Radiography Lecturers and Radiography Students towards the Proposed Curriculum. Biomed J Sci \& Tech Res 37(5)-2021. BJSTR. MS.ID.006063.

Keywords: Curriculum; Radiography; Perception; Doctor of Radiography

\section{ABSTRACT}

Objective: The objective of this study is to compare the perception of radiography lecturers and radiography students towards the proposed Doctor of Radiography curriculum.

Methodology: This study was carried out in all universities of Nigeria offering radiography as a course of study. The study population comprised of 62 radiography lecturers and 40 radiography students. A standard, self-structured questionnaire was used in the collection of data. The questionnaire comprised three sections. Section A obtained information on the demographic data of the lecturers and the students. Section $B$ elicited information on perceived knowledge of graduates of the D-RAD curriculum while section $C$ captured information on perceived quality of radiographers that will be produced by the D-RAD curriculum.

Results: A total of 62 lecturers comprising 51 males (82.3\%) and 11 females (17.7\%) and 40 students comprising 26 females (65\%) and 14 females (35\%) participated in the study. For the production of very knowledgeable radiographers, the lecturers and the students had means of 3.09 and 3.19 respectively. The lecturers and the students had means of 3.25 and 3.47 for the production of high quality radiographers. The means gotten were greater than the cut-off score that is 2.50 which was the mean derived from a 4-point Likert scale of Strongly Disagree-1 to Strongly Agree-4.

Conclusion: The proposed D-RAD curriculum will cover more content than the basic Bachelor's curriculum and ensure for the production of high quality and knowledgeable radiographers hence it is a welcome development for radiography lecturers and students.

\section{Introduction}

The word curriculum etymologically is derived from the Latin word 'curus' which means a racecourse taken by horses. In education, curriculum is conceived as a course taken in the

systematized educational process. The term 'curriculum' was coined by Franklin Bobbit in the year 1918. According to Bobbit, curriculum embodies experiences that the learner acquires in a 
learning institution [1]. Subsequently, curriculum has generally remained conceptualized as an instrument which embodies all those students undergo or pass through while pursuing any educational program. Even universities cannot be effectively run. Curriculum is regarded as the heart of learning institution [2]. Curriculum could be seen as a body of knowledge, as learning experiences, as a plan for action, learning outcomes or a process. According to Adirika and Okolie, curriculum is planned, guided learning experiences, and intended learning outcomes formulated through the systematic reconstruction of knowledge under the auspices of the school for the continuous and willful growth of the learner [3]. Curriculum is thus a programme which universities must run to properly educate the students. With curriculum, universities prepare students to acquire skills that would enable them to survive in their society. Hence, it should include a plan, a statement of purpose with a specification of contents and methods, inbuilt with the capacity for evaluation to know whether the purpose has been achieved or not. The curriculum of any institution of learning should be developed for the achievement of desired educational goals.

Curriculum development has a broad scope because it encompasses and considers the development of the school, the students, the teachers, and the society at large. Curriculum development is thus a planned, purposeful, progressive, and systematic process designed to create positive improvements in the educational system [2]. Since education is concerned with the advancement of man and the society, the curriculum developed to actualize this must possess the following five characteristics: purposeful aims and objectives, functionality, flexibility, relevance, and evaluation [4]. First, the aims and objectives of the curriculum to be developed must be clearly stated. A properly developed curriculum should also be workable, practicable and feasible. It should also be flexible hence, capable of adapting to the needs of the students and the society at large. Relevance is another characteristic of a properly developed curriculum. By relevance, the curriculum ought to emphasize the aspects that will be of great benefit to the students and the society. Students like to learn what would be useful to them. Evaluation thus becomes a very important characteristic a curriculum developer must consider. The developed curriculum should be evaluated to ensure that there is progress and that the progress is in the desired direction. This serves as a feedback for curriculum planners, implementers, and beneficiaries alike [2].

Radiography has undergone many transformations in recent years with a diversification in the role of the radiographers. The doctor of radiography curriculum is intended to introduce new areas like forensic radiography, computed tomography, film reporting, counseling skills, procurement and entrepreneurial skills and supply chain management which is role extension for radiographers. The doctor of radiography programme is expected to last for six sessions or twelve semesters unlike the basic bachelor's programme that lasts for five sessions or ten semesters. This is also obtained in other sister professions like Pharmacy, Medical rehabilitation, and Optometry. This is to keep in pace with other health professional groups academically. The Doctor of Radiography program is also expected to produce radiographers with professional competence, scientific competence, and sufficient managerial ability to perform excellently in hospital diagnostic services, public health services, research, and academics. Hence, produce graduates that will be able to function independently or in collaboration with other members of the health team. In the long run, the doctor of radiography programme with the help of a well-designed curriculum is expected to produce high quality professionals that can be part of the health team that make policies at the national and international levels. There is an urgent need for radiographers to be part of the team that make policies in the health sector so they can always protect the interest of the profession and the nation at large. The inclusion of radiographers in the health-policy making team will enhance the growth of the profession as bills promoting the growth of the profession will easily be passed into law while bills threatening the existence of the profession will be identified early and responded to; accordingly, since the radiography profession must adapt to the needs of the modern health sector and keep in pace with other health professional groups. The aim of this study is to compare the perception of radiography lecturers and radiography students towards the proposed Doctor of Radiography (D-RAD) curriculum.

\section{Methodology}

Participation in this cross-sectional study was voluntary and all were informed that their right to confidentiality and privacy would be adhered to. Ethical approval to carry out the study was obtained. Undergraduate students in their first, second and third years of study were excluded. The study population comprised radiography lecturers $(n=62)$ and radiography students in their fourth and fifth years $(n=40)$ in both public and private universities in Nigeria. A standard self-structured questionnaire was used for the study. Cronbach alpha test for internal consistency of items was applied in checking the reliability of the instrument. The Cronbach alpha coefficient value was 0.92 . The high co-efficient value was an indication of the internal consistency of the instrument, which was considered satisfactory for the study. The questionnaire comprised of 3 sections. Section A contained closed questions which were used to obtain the demographic data of the lecturers and students. Section B comprised of questions on perceived knowledge of graduates of the D-RAD curriculum. Section $\mathrm{C}$ captured information on perceived quality of radiographers that will be produced by the D-RAD curriculum. This required the participants to rate their level of perception on a 4-point Likert scale of Strongly Agree-4 to Strongly Disagree-1. 
Statistical analysis was done using Statistical Package for Social Sciences version 23. Descriptive statistics like frequencies and percentages were used to describe the demographic characteristics of the participants. Mean and standard deviation were used to determine the perception of the lecturers and the students on the ability of the D-RAD curriculum to produce very knowledgeable and high-quality radiographers. A mean of 2.50 (which was the mean gotten from the 4-point Likert scale of Strongly Agree-4, Agree-3, Diagree-2, Strongly Disagree-1) and above was accepted. Independent sample t-test was used to ascertain if there was a statistically significant difference in the ratings of the two categories of lecturers on perceived knowledge and quality of radiographers that will be produced by the Doctor of radiography curriculum. A p-value less than 0.05 was used as a criterion for statistical significance.

\section{Results}

Table 1 shows the demographic data of the lecturers. The lecturers were categorized by gender, age, rank, lecturing experience, and highest educational attainment. From the table, a total of 51 male and 11 female lecturers $(n=62)$ participated in the study. 33 lecturers $(53.2 \%)$ were within the age range of 2135 years, 18 lecturers (29.0\%) were within 36-50 years while 11 lecturers $(17.8 \%)$ were above 50 years of age. Lecturers that had B.Sc as their highest educational attainment were 10 (16.2\%) in number, those that had M.Sc were 31 (50\%) in number while those with Ph.D were 21 (33.8\%) in number. Table 2 shows the demographic data of the students. The students were categorized by gender, age, and level of study. From the table, a total of 40 students comprising 26 males (65\%) and 14 females (35\%) participated in the study. 5 students (12.5\%) were within 16-20 years, 28 students (70\%) were within 21-25 years while 7 students (17.5\%) were above 25 years. 20 students $(50 \%)$ were in their fourth year while 20 students $(50 \%)$ were in their fifth year of study. Table 3 shows the mean comparison of lecturers and students' perception on knowledge of graduates of the D-RAD curriculum. The lecturers had a mean of 3.03 while the students had a mean of 3.19 (A mean of $>2.50$ shows an agreement). This shows that both the lecturers and the students agree that the D-RAD curriculum will produce very knowledgeable radiographers.

Table 1: Demographic data of the lecturers.

\begin{tabular}{|c|c|c|}
\hline Variables & Frequency & Percentage \\
\hline \multicolumn{3}{|l|}{ Gender } \\
\hline Female & 11 & 17.7 \\
\hline Male & 51 & 82.3 \\
\hline Total & 62 & 100.0 \\
\hline \multicolumn{3}{|l|}{ Age (Years) } \\
\hline $21-35$ & 33 & 53.2 \\
\hline $36-50$ & 18 & 29.0 \\
\hline$>50$ & 11 & 17.8 \\
\hline Total & 62 & 100.0 \\
\hline \multicolumn{3}{|l|}{ Rank } \\
\hline Assist. Lecturers & 19 & 30.6 \\
\hline Lecturers II and I & 28 & 45.2 \\
\hline Senior Lecturers & 11 & 17.7 \\
\hline Readers and Professors & 4 & 6.5 \\
\hline Total & 62 & 100.0 \\
\hline \multicolumn{3}{|l|}{ Lecturing Experience (Years) } \\
\hline $1-10$ & 48 & 77.4 \\
\hline $11-20$ & 10 & 16.1 \\
\hline $21-30$ & 3 & 4.8 \\
\hline Above 30 & 1 & 1.6 \\
\hline Total & 62 & 100.0 \\
\hline \multicolumn{3}{|c|}{ Highest Educational Attainment } \\
\hline B.Sc. & 10 & 16.2 \\
\hline M.Sc. & 31 & 50.0 \\
\hline Ph.D. & 21 & 33.8 \\
\hline Total & 62 & 100.0 \\
\hline
\end{tabular}


Table 2: Demographic data of the students.

\begin{tabular}{|c|c|c|}
\hline Variables & Frequency & Percentage \\
\hline Gender & & 35.0 \\
Female & 14 & 65.0 \\
Male & 26 & 100.0 \\
Total & 40 & 12.5 \\
\hline Age (Years) & 5 & 70.0 \\
$16-20$ & 28 & 17.5 \\
$21-25$ & 7 & 100.0 \\
$>25$ & 40 & 50.0 \\
Total & & 50.0 \\
\hline Year of Study & 20 & 100.0 \\
\hline Fourth year & 20 & \\
\hline Fifth year & 40 & \\
\hline
\end{tabular}

Table 3: Perception of lecturers and students on knowledge of radiographers.

\begin{tabular}{|c|c|c|c|c|}
\hline \multirow{2}{*}{ Items on knowledge } & \multicolumn{2}{|c|}{ Mean values } & \multirow{2}{*}{ t-values } & \multirow{2}{*}{ p-values } \\
\hline & Lecturers & Students & & \\
\hline Increased knowledge & 3.03 & 3.50 & -2.124 & $0.036^{*}$ \\
\hline Increased versatility & 3.00 & 3.57 & -2.591 & $0.011^{*}$ \\
\hline Coverage of more content & 3.45 & 3.25 & 1.032 & 0.305 \\
\hline Greater exposure to ideas & 3.06 & 3.30 & -1.077 & 0.284 \\
\hline Better opportunity to research deeply & 3.13 & 3.25 & -0.558 & 0.578 \\
\hline Ability to focus on their interest areas & 2.94 & 3.62 & -3.114 & $0.002 *$ \\
\hline Effective discussion of issues in their areas of interest & 2.98 & 3.33 & -1.500 & 0.137 \\
\hline Ability to address problem areas in radiography & 2.63 & 3.22 & -2.158 & $0.033^{*}$ \\
\hline Ability to compete favorably in the labour market & 3.10 & 2.72 & 1.384 & 0.169 \\
\hline Ability to meet up with the demands of the modern health sector & 2.90 & 3.12 & -0.829 & 0.409 \\
\hline Ability to compete favorably with their contemporaries internationally & 2.94 & 2.83 & 0.452 & 0.653 \\
\hline In-depth scientific background to enrich Radiography practice & 2.94 & 3.33 & -1.708 & 0.091 \\
\hline Production of radiographers with higher professional competence & 3.08 & 3.50 & -2.003 & $0.048^{*}$ \\
\hline Production of radiographers with sufficient management ability & 2.48 & 3.18 & -2.789 & $0.006^{*}$ \\
\hline Possession of basic entrepreneurial skills & 2.31 & 2.10 & 0.695 & 0.489 \\
\hline Production of radiographers that can report medical images effectively & 2.19 & 3.35 & -4.289 & $0.000^{*}$ \\
\hline Ability to coordinate the activities of other radiographers. & 2.63 & 3.10 & -1.802 & 0.075 \\
\hline Mean & 3.03 & 3.19 & & \\
\hline
\end{tabular}

*Significant $\mathrm{p}<0.05$

Table 4 shows the mean comparison of lecturers and students perception on the quality of radiographers that will be produced by the D-RAD curriculum. The lecturers had a mean of 3.25 while the students had a mean of 3.47 (A mean of $>2.50$ shows an agreement). This shows that both the lecturers and the students agree that the D-RAD curriculum will produce high quality radiographers that can better contribute to policy formulation and implementation. Table 5 shows independent sample t-test of the two categories of lecturers on the perceived knowledge of students of the D-RAD curriculum. The $p$-value was $0.056(p>0.05)$. This implies that there is no significant difference in the mean ratings of perceived knowledge level between the higher cadre lecturers and the lower cadre lecturers. Hence, the null hypothesis was accepted. Table 6 shows the independent sample t-test of the two categories of lecturers on the perceived quality of professionals that will be produced by the D-RAD curriculum. The $p$-value was 0.063 ( $p>0.05$ ). This implies that there is no significant difference in the mean ratings of the two categories of lecturers on the perceived quality of professionals that will be produced by the D-RAD curriculum. Hence, the null hypothesis was accepted. 
Table 4: Perception of lecturers and students on quality of radiographers.

\begin{tabular}{|c|c|c|c|c|}
\hline \multirow{2}{*}{ Items on quality } & \multicolumn{2}{|c|}{ Mean values } & \multirow{2}{*}{ t-values } & \multirow{2}{*}{ p-values } \\
\hline & Lecturers & Students & & \\
\hline Competence in three imaging modalities. & 3.10 & 3.55 & -2.178 & $0.032^{*}$ \\
\hline Ability to rise to the highest level in public service. & 3.44 & 3.50 & -0.444 & 0.658 \\
\hline The radiographers can contribute to policy formulation. & 3.26 & 3.60 & -2.084 & $0.040^{*}$ \\
\hline The radiographers can enhance policy implementation. & 3.15 & 3.38 & -1.188 & 0.238 \\
\hline Ability to command respect like their medical counterparts & 3.00 & 3.58 & -2.867 & $0.005^{*}$ \\
\hline Ability to perform effectively in hospital diagnostic services & 3.47 & 3.33 & 0.923 & 0.358 \\
\hline Ability to perform effectively in public health services & 3.23 & 3.48 & -1.384 & 0.169 \\
\hline The radiographers can function independently in the discharge of duties & 3.08 & 3.30 & -1.066 & 0.289 \\
\hline Collaboration with other members of the health team & 3.48 & 3.53 & -0.351 & 0.727 \\
\hline Mean & 3.25 & 3.47 & & \\
\hline
\end{tabular}

*Significant $\mathrm{p}<0.05$

Table 5: Independent sample t-test of the two categories of lecturers on perceived knowledge of radiographers.

\begin{tabular}{|c|c|c|c|c|c|}
\hline Ranks & N & Mean & SD & t-value & Decision \\
\hline Lower cadre lecturers & 47 & 2.9908 & 0.82 & 1.952 & 0.056 \\
\hline Higher cadre lecturers & 15 & 2.4941 & 0.98 & \\
\hline Total & 62 & & & \\
\hline
\end{tabular}

NS = Not Significant

Table 6: Independent sample t-test of the two categories of lecturers on perceived quality of professionals produced.

\begin{tabular}{|c|c|c|c|c|c|}
\hline Rank & N & Mean & SD & t-value & Decision \\
\hline Lower cadre lecturers & 47 & 3.3357 & .63215 & 1.896 \\
\hline Higher cadre lecturers & 15 & 2.9556 & .80431 & & \\
\hline Total & 62 & & & \\
\hline
\end{tabular}

NS = Not Significant

\section{Discussion}

From this study, the graduates of the D-RAD curriculum will exhibit increased knowledge in all radiography specialties than the graduates of the basic bachelor's curriculum. This is like the findings by Raupach et al. who carried out a study on the impact of an undergraduate cardio-respiratory curriculum on the knowledge of students [5]. A virtual problem-based learning environment for the students was created. It was discovered that additional problembased learning with an online module as part of an undergraduate cardio-respiratory curriculum led to an increased knowledge of the students. The knowledge of the students is expected to increase because online classes are almost as effective as physical contact classes. The result of this study is also in line with the study carried out by Morrison et al. that assessed the impact of a palliative care curriculum on knowledge of medical students [6]. Validated multiple choice palliative care pain management items were administered to measure the knowledge of the students. The students demonstrated a statistically significant increase in knowledge hence it was recommended that the curriculum be inculcated into the programme of the students. It is expected that the knowledge the students had after being exposed to the curriculum will be higher than their knowledge before exposure to the curriculum. The result of this study disagrees with the study done by Carolyn et al. who assessed the knowledge of medical students after completion of an integrated nutrition curriculum at Harvard Medical School [7]. A survey of the students was carried out and their knowledge was rated. It was discovered that there was no significant change in the nutrition knowledge of the students after receiving the integrated nutrition curriculum. This could be due to poor lecture delivery. If the instructional methods and materials are inadequate, the students might not add any new knowledge to what they knew before.

The result of this study showed that the D-RAD curriculum will be able to produce high quality radiographers that can better contribute to policy formulation and implementation. This is similar to the findings by Abdulaziz who carried out a study on radiography 
education and training and found out that a high quality program for radiographers is necessary to produce competent radiographers for both diagnostic and therapeutic working environment [8]. Hence, there is a need to review radiography education and training so as to fulfill the needs of the modern health sector. Also, Mumbo and Kinaro carried out a study on assessment of the relevance of curricula development in health training institutions [9]. According to the researchers, strengthening of health training institutions to increase the quality of health workers produced is very important and ensures access to universal quality health coverage. This entails design and constant reviews of their curriculum to meet the needs of the modern health sector.

\section{Conclusion}

Both the radiography lecturers and the students showed a positive perception towards the proposed D-RAD curriculum. The study discovered that the D-RAD curriculum will produce radiographers with higher knowledge and broader orientation in radiography. It is also perceived that the D-RAD curriculum will produce high quality radiographers that can contribute to policy formulation and implementation.

\section{Declaration of Conflicting Interests}

The authors declared no potential conflicts of interest with respect to the research, authorship and/or publication of this article.

\section{ISSN: 2574-1241}

DOI: 10.26717/BJSTR.2021.37.006063

Beatrice Ukamaka Maduka. Biomed J Sci \& Tech Res

(c) (9) This work is licensed under Creative

Submission Link: https://biomedres.us/submit-manuscript.php

\section{Funding}

The authors received no financial support for the research, authorship and/or publication of this article.

\section{References}

1. Bobbitt F (1918) The curriculum. Boston: Houghton Mifflin.

2. Alvior MG (2014) The meaning and importance of curriculum development.

3. Adirika BN, Okolie VC (2017) Examining models of curriculum development and processes: Implications for African educational heritage and review. Soci Sci and Human J 1(6): 325-342.

4. Onwuka U (1990) Curriculum development for Africa. Onitsha: AfricanaFeb Publishers Ltd.

5. Raupach T, Munscher C, Pukrop T, Anders S, Harendza S (2010) Significant increase in factual knowledge with web-assisted problembased learning as part of an undergraduate cardio-respiratory curriculum. Adv Health Sci Edu Theory Pract 15(3): 349-356.

6. Morrison LJ, Thompson BM, Gill AC (2012) A required third-year medical student palliative care curriculum impacts knowledge and attitudes. J Palliat Med 15(7): 784-789.

7. Carolyn OW, Sonja IZ, Helen KD, David SL (2011) Nutrition attitudes and knowledge in medical students after completion of an integrated nutrition curriculum compared to a dedicated nutrition curriculum: A quasi-experimental study. BMC Med Educ 11: 58.

8. Abudulaziz SA (2012) Radiography education and training in Saudi Arabia. Open J Radiol 2(4):134-140.

9. Mumbo HM, Kinaro JW (2015) Assessment of quality and relevance of curricula development in health training institutions: A case study of Kenya. Human Resources for Health 13(1): 67-77.

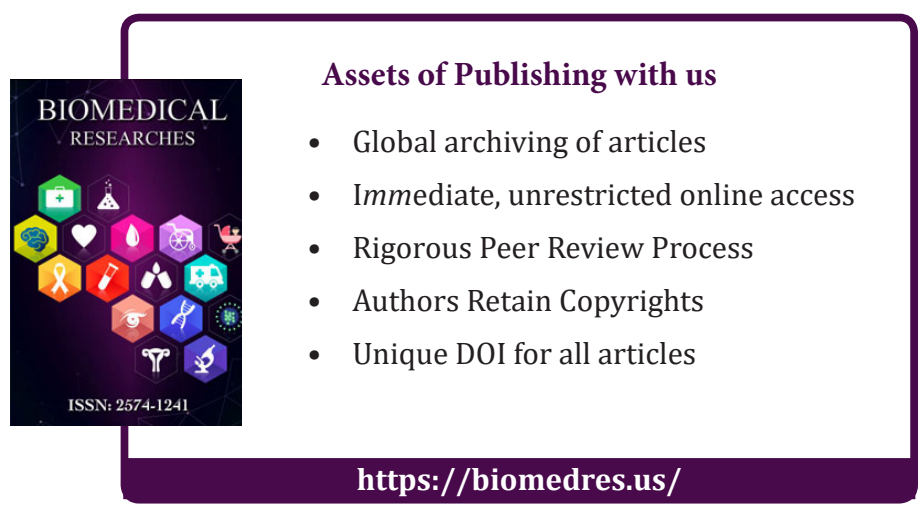

